\title{
AS CONCEPÇÕES DE HOMEM, NATUREZA E TRABALHO NO CURSO TÉCNICO EM MEIO AMBIENTE DO IFSUL
}

\author{
Christiano Nogueira ${ }^{1}$ \\ Susana Inês Molon²
}

\begin{abstract}
Resumo
Este artigo apresenta o resultado de uma pesquisa sobre as concepções de homem, natureza e trabalho que relaciona as compreensões de Educação Ambiental e Educação Profissional de doze concluintes do curso Técnico em Meio Ambiente do Instituto Federal Sul-rio-grandense. Os alunos foram entrevistados, e as inferências foram construídas a partir da metodologia Análise de Conteúdo. As categorias de análise utilizadas foram: homem, trabalho e natureza. Emergiram as unidades de análise: Homem produz impactos à natureza; Relação trabalho, emprego e natureza e; Perspectiva interdisciplinar. Os resultados mostram que, no curso, há a compreensão de uma cisão existente entre o homem e a natureza, o trabalho como exploração da natureza causando impactos e a formação relacionada aos interesses do mercado. Essas concepções de homem, natureza e trabalho implicam em perspectivas de uma Educação Ambiental voltada ao mercado, através da conscientização para diminuir os impactos ambientais e de uma Educação Profissional voltada às necessidades do processo produtivo.
\end{abstract}

Palavras-chave: Educação ambiental. Educação profissional. Formação integrada.

\section{THECONCEPTS OF MAN, NATURE ANDWORK IN THETECHNICIAN IN ENVIRONMENT COURSE OF IFSUL}

\begin{abstract}
This paper presents the results of a research on the concepts of man, nature and work that relates to the understanding of Environmental Education and Professional Education of twelve students Technician Environment of the Instituto Federal Sul-rio-grandense. Students were interviewed and methodologically used the Content Analysis .The analysis categories were: man, work and nature. Emerged the units of analysis: Man produces impacts on nature; Relation work, employment and nature and; Interdisciplinary perspective. The results show that in the course there is an understanding of an existing division between man and nature, work as exploitation of nature impacting and training related to market interests. These conceptions of man, nature and work imply perspectives of an environmental education oriented to the market through awareness to reduce the environmental impacts and a professional education oriented to the needs of the production process.
\end{abstract}

Keywords: Environmental education. Professional education. Integrated formation.

\footnotetext{
${ }^{1}$ Professor da Universidade Federal do Paraná, Setor Litoral.

${ }^{2}$ Professora do Programa de Pós-graduação em Educação Ambiental da Universidade Federal do Rio Grande.
} 


\title{
LOS CONCEPTOS DE HOMBRE, NATURALEZA Y TRABAJO EN EL CURSO TÉCNICO EN \\ MEDIO \\ AMBIENTE DE LA IFSUL
}

\begin{abstract}
Resumen
Este artículo presenta los resultados de una investigación sobre los conceptos de hombre, naturaleza y trabajo que relaciona la comprensiones de Educación Ambiental y Educación Profesional de doce graduados del curso técnico en medio ambiente del Instituto Federal de Sul-rio-grandense. Los estudiantes fueron entrevistados, y las inferencias se construyen a partir de la metodología de Análisis de Contenido. Las categorías de análisis fueron: el hombre, el trabajo y la naturaleza. Fueron obtenidas las unidades de análisis: el hombre produce impactos sobre la naturaleza; relación trabajo, empleo y naturaleza; perspectiva interdisciplinaria. Los resultados muestran que en el cursoprevaleció una comprensión de una división existente entre el hombre y la naturaleza, el trabajo como la explotación de la naturaleza, causando impactos, y formación relacionada con los intereses del mercado. Estas concepciones del hombre, naturaleza y trabajo implican perspectivas de educación ambiental dirigidas al mercado, a través de la sensibilización para reducir los impactos ambientales, y una formación profesional orientada a las necesidades del proceso de producción.
\end{abstract}

Palabras-clave: Educación ambiental. Educación profesional. Formación integrada.

\section{Introdução}

A Educação Ambiental e a Educação Profissional estão inseridas em um contexto de conflitos de interesses políticos e contradições da sociedade que, por um lado, atende as demandas de qualificação para o mercado de trabalho, aquecido pelo capitalismo desenvolvimentista, e, por outro, visa à construção de uma sociedade igualitária com equilíbrio ambiental através de um metabolismo na relação entre o homem e natureza.

Nesse sentido, este artigo trata das concepções de homem, de natureza e de trabalho, que implicam em perspectivas de Educação Ambiental e de Educação Profissional do curso de Técnico em Meio Ambiente do campus Pelotas-Visconde da Graça no Instituto Federal Sul-rio-grandense.

O curso de Técnico em Meio Ambiente iniciou-se em 2010, quando o atual campus Pelotas-Visconde da Graça era ainda denominado Conjunto Agrotécnico Visconde da Graça, e estava vinculado à Universidade Federal de Pelotas. Na primeira versão do projeto pedagógico, a duração prevista era de três anos, com carga horária total de 4.920 horas, sendo ofertadas 35 vagas anualmente. Por tratar-se de um curso integrado, essa carga horária contempla tanto as disciplinas de formação do nível médio, como as de formação específica. Segundo o projeto pedagógico, o curso possuía a característica de transversalidade da área do meio ambiente, e sua estruturação foi baseada em cinco eixos de formação: a) Ciências Ambientais; b) Gestão e Legislação; c) Ecoturismo; d) Química Ambiental; e) Agente Socioambiental. Para cada eixo, ainda, estabeleceram-se as competências e habilidades necessárias que estão associadas às disciplinas de formação específica do curso.

$\mathrm{Na}$ versão atual do projeto pedagógico, reconstruído devido à vinculação com o IFSul, a carga horária total é de 3.360 horas e também com duração de três anos. Devido a essa adequação, o projeto pedagógico apresenta as disciplinas com suas respectivas ementas, ao invés de apresentar as competências e habilidades, como estava no projeto anterior.

As concepções de homem, natureza e trabalho fazem parte de uma totalidade em que a Educação Ambiental e a Educação Profissional englobam, conjuntamente, o processo formativo de técnicos,possibilitando a transformação das relações sociais em que o trabalho e 
a natureza sejam tratados dentro das necessidades básicas do homem e não do processo produtivo.

\section{Procedimentos metodológicos}

Os alunos do curso, sujeitos da pesquisa, estavam matriculados no último ano. Essa opção se deu por entendermos que, a partir dos processos formativos ocorridos nos dois primeiros anos, eles já possuíam construídas as suas concepções de homem, natureza e trabalho e, consequentemente, sobre Educação Ambiental e Educação Profissional.

Foram realizadas entrevistas conforme o agendado com os alunos, as quais ocorreram sem imprevistos, entre 28 de março e 9 de abril de 2014, no campus Pelotas-Visconde da Graça. Um questionário foi utilizado como base para as entrevistas. As perguntas desse questionário foram direcionadas para conhecer os efeitos práticos do currículo dos cursos; compreender como os alunos vivenciam a prática de sua futura profissão; compreender como ocorre o processo interdisciplinar nos cursos; compreender como os alunos entendem a relação entre o homem e a natureza; compreender como os alunos poderiam resolver problemas de questões ambientais, considerando fatores políticos, econômicos e sociais; compreender o significado de meio ambiente e natureza; averiguar oque eles entendem por Educação Ambiental.

As entrevistas foram gravadas e também foram realizadas anotações no seu transcorrer, mediante autorização do entrevistado. Após, foram realizadas as transcrições. Depois da transcrição das entrevistas, foi realizada a leitura desses documentos, analisando os textos, parágrafos e comentários dos sujeitos entrevistados, visando à categorização dos dados, que foram organizados inicialmente em planilhas.

As entrevistas foram objeto da análise e interpretação dos dados, com basena Análise de Conteúdo (BARDIN, 1977; FRANCO, 2005). Esse tipo de análise constitui-se num processo em que os textos originais, numa primeira etapa, passam pela desconstrução, que consiste no exame detalhado e na fragmentação do texto em unidades de base, e, em seguida, pela categorização, que estabelece uma nova relação entre essas unidades de base, permitindo o agrupamento de elementos semelhantes, bem como condições para uma maior profundidade na análise e interpretação dos dados.

\section{0 referencial teórico}

Para uma melhor análise das concepções de homem, de natureza e de trabalho, e as perspectivas de Educação Ambiental e de Educação Profissional do curso tratado, apresentamos, separadamente, essas duas perspectivas a seguir.

\subsection{A Educação Ambiental}

Atualmente, encontram-se diferentes descrições e mapeamentos das correntes de Educação Ambiental. São várias identificações, classificações e definições das suas diversas tendências. A caracterização das concepções de Educação Ambiental está influenciada por diferentes concepções epistemológicas de meio ambiente e natureza, que são constituídas por diferentes contextos e situações sociais, políticas e históricas. A partir disso, apresentamos algumas descrições de autores que realizaram estudos aprofundados e podem contribuir, significativamente, para essa compreensão.

Uma cartografia das correntes de Educação Ambiental é apresentada por Sauvé (2005), em um contexto norte-americano e europeu. Essa autora refere-se à noção de corrente a uma maneira geral de conceber e praticar a Educação Ambiental e, embora cada corrente 
possua um conjunto de características específicas, fazendo-a diferenciar-se das outras, algumas compartilham características comuns, ou seja, não são mutuamente excludentes. Nessa cartografia, a autora considera, para não correr o risco de deformar a realidade, que seja uma classificação em categorias que não obedeçam a uma rigidez. Apresentamos, a seguir, aquelas com maior destaque no cenário da Educação Ambiental e pertinentes ao contexto desta pesquisa.

A corrente Conservacionista/Recursista está centrada em proposições focadas na conservação dos recursos, tanto em relação à qualidade quanto à quantidade. "Quando se fala de 'conservação da natureza', como biodiversidade, trata-se sobretudo de uma naturezarecurso. Encontra-se aqui uma preocupação com a "administração do meio ambiente", ou, melhor dizendo, de gestão ambiental'(SAUVÉ, 2005, p. 20). Os comportamentos individuais e projetos coletivos fazem parte das ações imperativas. Nessa concepção estão contemplados os programas de Educação Ambiental centrados nos três $R$, muito conhecidos, quais sejam: Redução, Reutilização e Reciclagem.

A corrente Resolutiva de Educação Ambiental está centrada em estudos das problemáticas ambientais, considerando os componentes sociais e biofísicos com suas controvérsias inerentes, ou seja, agrupa proposições relacionadas ao meio ambiente, considerado, principalmente, como um conjunto de problemas. A visão central de Educação Ambiental dessa corrente é a proposta pela UNESCO, no contexto de seu Programa Internacional de Educação Ambiental (1975-1987).

A corrente da Sustentabilidade, segundo seus partidários, estaria limitada a um enfoque naturalista, sem contemplar preocupações sociais, particularmente as econômicas, ao tratar das problemáticas ambientais, sendo a educação para o desenvolvimento sustentável uma forma de atenuar essa carência. Assim, a Educação Ambiental, nessa perspectiva, é tratada como um objeto de política econômica. Ela deve responder às necessidades do desenvolvimento sustentável, que consiste na formação de recursos humanos que favoreçam mudanças sociais e econômicas.

Essas perspectivas apresentam características de uma natureza desvinculada do homem. Essas características aparecem ao proporem que haja uma aproximação com a natureza, uma preservação dos recursos naturais, um tratamento científico, a reciclagem etc. Envolve a perspectiva de Educação Ambiental que legitima a forma de organização da sociedade, consolidando, assim, uma naturalização das diferenças de classes e do processo produtivo, que possui relação direta com o meio ambiente. Ou seja, mesmo perspectivas como essas, que incluem abordagens interdisciplinares e transdisciplinares envolvendo aspectos sociais, não tratam da relação entre o homem e a natureza em sua processualidade, em que "a natureza assim assume significado prático para a humanidade como resultado da atividade de vida, a produção do meio de vida" (FOSTER, 2011, p. 107-108). Não consideram o trabalho humano como agente da transformação da natureza pelo homem e, consequentemente, uma possibilidade de transformação da sociedade e sua relação com a natureza.

Encontram-se, ainda, outras vertentes. A perspectiva de Educação Ambiental categorizada como Ecopedagogia é defendida por autores como Ruscheinsky (2004) e Avanzi (2004). A Ecopedagogia é compreendida com base no pensamento crítico e inovador, promovendo a transformação e a construção da sociedade, envolvendo a individualidade e a coletividade em uma perspectiva holística, com foco interdisciplinar na relação entre o ser humano e a natureza. Também na Ecopedagogia, a Educação Ambiental deve estimular a solidariedade, a igualdade e o respeito aos direitos humanos, ajudando no desenvolvimento de uma consciência ética em relação a todas as formas de vida, respeitando seus ciclos vitais e impondo limites à exploração dessas formas de vida. Essa perspectiva de Educação Ambiental envolve aspectos que promovamuma mudança social com vistas à superação das forças 
opressoras, possibilitando a igualdade entre sujeitos e uma relação equilibrada entre o homem e a natureza.

A concepção de Educação Ambiental Crítica é defendida por vários autores brasileiros, que apresentam diferenças nas suas construções teóricas. A seguir, aborda-se a posição de Isabel Carvalho, Mauro Guimarães e Carlos Frederico Loureiro sobre a Educação Ambiental Crítica.

Carvalho (2004) desenvolve a concepção de Educação Ambiental Crítica como superação da visão ingênua da Educação Ambiental. Nessa perspectiva, a Educação Ambiental é considerada com sua legitimidade devido à especificidade da prática educativa ambientalmente orientada,e seu papel crítico ao se compreender as relações entre a sociedade e a natureza para intervir sobre os problemas e conflitos ambientais. Os aspectos políticos e pedagógicos da Educação Ambiental Crítica favoreceriamuma mudança de valores e atitudes, que contribuiria para a formação de um sujeito ecológico. A formação dos sujeitos estaria orientada por sensibilidades solidárias com o meio social e ambiental, servindo como modelo para a formação de sujeitos e grupos sociais que possuam capacidades de identificar, problematizar e agir em relação às questões socioambientais, com a finalidade de uma ética preocupada com a justiça ambiental.

Para Carvalho (2004), a prática educativa da Educação Ambiental Crítica é formar o sujeito em sua dimensão individual e social, considerando-o como um sujeito histórico. A educação não está focada, de forma exclusiva, no indivíduo como um ser único, bem como em um coletivo tratado de forma abstrata. Essa perspectiva vai contra a crença de que as mudanças sociais ocorrem através da soma das mudanças individuais, como a soma de cada um fazendo sua parte. Embora essa perspectiva considere o sujeito histórico com uma formação crítica, os fundamentos teóricos dessa autora não consideram a formação dos sujeitos através doprocesso dialético em que se permita superar as relações de produção na sociedade capitalista.

Guimarães (2004) também categoriza uma concepção de Educação Ambiental Crítica através de uma construção teórica de contraposição a algo existente, no sentido de superação de outra perspectiva categorizada como Educação Ambiental Conservadora. Essa perspectiva de Educação Ambiental está relacionada a uma compreensão e a uma postura educacional e de mundo, a partir de um paradigma e ideologia que se manifestam, hegemonicamente, na constituição da sociedade contemporânea. A construção da perspectiva de Educação Ambiental Crítica desse autor fundamenta-se em ideias de que a Educação Ambiental Conservadora não é instrumentalizada sob o ponto de vista epistemológico, não é comprometida com o processo de transformações significativas da realidade socioambiental, por estar presa em suas perspectivas ideológicas.

Como superação dessa perspectiva, Guimarães (2004) desenvolve a concepção de Educação Ambiental Crítica como necessária para que haja diferenciação de uma ação educativa, com capacidade de transformação da realidade social, bem como suas relações com meio ambiente, que está em crise conforme processos históricos. Nesse sentido, essa perspectiva de Educação Ambiental possibilitaria direcionar para a superação de uma sociedade com tendência fragmentária, dualista e dicotômica. Assim, essa perspectiva é vista como uma contraposição, segundo outro referencial epistemológico, que permite subsidiar uma interpretação da realidade mais complexa e instrumentalizada, para uma intervenção que contribua no processo de transformação da realidade socioambiental que é complexa.

A Educação Ambiental Crítica, para Loureiro (2009), é aquela categorizada por não derivar de saberes desunidos e compartimentalizados. Nessa perspectiva, há a compreensão de que a apreensão da realidade deva ocorrer segundo algumas categorias conceituais que são indissociáveis aos procedimentos pedagógicos. A Educação Ambiental deve considerar o contexto envolvido ao se abordar sobre um conceito ou temática. O global como um 
significado de conjunto das relações em que estamos inseridos. $\mathrm{O}$ multidimensional como uma percepção do ser humano como um ser biológico, social, psicológico, cultural etc., com sua vivência na sociedade, com sua historicidade e o complexo "enquanto união de elementos distintos inseparavelmente constitutivos do todo" (LOUREIRO, 2009, p. 93-94). A Educação Ambiental não é apolítica e deve considerar, no processo formativo dos sujeitos, uma construção de concepções de homem, natureza e trabalho que promova uma transformação na sociedade com igualdade social e equilíbrio ambiental.

Outra possibilidade de definição é a Educação Ambiental Emancipatória e Transformadora, apresentada na perspectiva de Quintas (2004) e de Loureiro (2004, 2009). A concepção de educação nos processos de gestão ambiental é desenvolvida por Quintas (2004) como Educação Ambiental Emancipatória e Transformadora.Trata-se de uma educação comprometida em construir um futuro sustentável, que possua como fundamento o meio ambiente, sendo entendido como ecologicamente equilibrado e direito de todos, bem de uso comum e essencial à qualidade de vida saudável. Isso implica construir uma sociedade com um estilo de desenvolvimento que seja socialmente justo e ambientalmente seguro, em um contexto de dependência econômica e exclusão social. A prática de uma gestão ambiental que seja democrática, com o pressuposto de que todas as espécies possuem o direito à vida, que enfrenta os desafios de uma sociedade de privilégios para poucos e obrigações para muitos.

A Educação Ambiental Emancipatória e Transformadora, segundo Quintas (2004), entende a gestão ambiental como um processo de mediação de interesses e conflitos entre sujeitos que disputam o acesso e uso dos recursos do meio ambiente. Nesse contexto, a gestão ambiental não é neutra e o Estado, ao se deparar com a problemática ambiental, define quem ficará com os custos ou benefícios que provem da ação humana no meio ambiente. A prática da gestão ambiental pelo Estado faz com que haja uma distribuição assimétrica na sociedade, seja no tempo e no espaço. A sociedade é entendida não como um lugar de harmonia, mas, de confrontos e conflitos que envolvem as esferas da política, da economia, das relações sociais, dos valores etc. A percepção dos problemas ambientais, bem como a aceitação da existência destes, não apontam para uma questão cognitiva, mas, sim, para a prevalência deinteresses econômicos, político e ideológicos relacionados a um meio social e político.

A estruturação do processo educativo, nessa perspectiva, se estrutura no sentido de superação da compreensão fragmentada da realidade por meio de uma construção e reconstrução que abranjamum processo reflexivo entre os sujeitos envolvidos; o respeito à pluralidade e diversidade cultural, fortalecendo a ação coletiva e organizadae articulando os diferentes saberes e fazeres para proporcionar a compreensão dos problemas ambientais em toda a sua complexidade; a possibilidade da ação conjunta com a sociedade civil organizada, principalmente com os movimentos sociais, de forma que haja uma compreensão de Educação Ambiental, com sua característica interdisciplinar, como um processo que institui novas relações entre os sujeitos e a natureza.

Loureiro (2004) caracteriza a Educação Ambiental, para fins didáticos, por blocos de tendências, como Educação Ambiental Convencional e Educação Ambiental Transformadora. $\mathrm{Na}$ primeira, a Educação Ambiental é compreendida, de forma enfática, na dimensão individual dos sujeitos e está baseada em vivências práticas de sensibilização, sendo as relações sociais tratadas de forma secundária ou com baixa compreensão. Os processos educativos são tratados como atos comportamentais com pouca articulação com o coletivo e problematização para transformação da realidade de vida, fazendo com que esses processos sejam despolitizados. Isso faz com que haja uma crença ingênua de que as mudanças objetivas ocorram através das mudanças individuais sem a compreensão das relações sociais mais complexas. O ser social é tratado como um organismo biológico, sem suas características históricas e sociais. Isso ocorre através do que Loureiro chamou de biologização do ser social. Assim, a responsabilidade pela degradação do meio ambiente é posta a um ser humano 
genérico, idealizado, a-histórico, que seria descontextualizado socialmente(LOUREIRO, 2004).

Assim, no entendimento desse autor, a mudança através dos processos educativos no sentido de superar a Educação Ambiental Convencional seria possível através da outra vertente, ou seja, a Educação Ambiental Transformadora. Segundo Loureiro (2004), nessa vertente a formação do sujeito deve contemplar a capacidade crítica aliada à compreensão de que ele faz parte da natureza. Também, que suas decisões conjuntamente com outros sujeitos implicam, de forma direta ou indireta, no meio ambiente. Além disso, essa compreensão deve ocorrer entre sujeitos de forma livre e sem as influências coercitivas. A Educação Ambiental Transformadora, para Loureiro (2009, p. 89), “é aquela que possui um conteúdo emancipatório, em que a dialética entre forma e conteúdo se realiza de tal maneira que as alterações da atividade humana, vinculadas ao fazer educativo, impliquem em mudanças" e, assim, essa Educação Ambiental é uma práxis social que poderá permitir uma construção de novas relações de produção, que estará relacionada a um novo modelo econômico, social, cultural e histórico com centralidade na atuação política dos sujeitos.

Nessa perspectiva, a Educação Ambiental não pode ignorar as relações existentes entre diferentes grupos sociais, com seus respectivos interesses que também são diferentes, grupos estes que possuem diferentes condições nos conflitos de interesses. Dessa forma, a Educação Ambiental Transformadora não permite soluções compatibilistas, existentes entre o ambientalismo e o capitalismo, bem como quaisquer encaminhamentos moralistas que desvinculem o comportamento dos indivíduos com suas características históricas e culturais de vivência em sociedade.

\subsection{A Educação Profisssional}

Ao se analisar a Educação Profissional, não se pode deixar de considerá-la num contexto social, político e econômico de uma sociedade que obedece a um modo de produção em que o trabalho intelectual está separado do trabalho manual, e essa separação oculta uma materialidade que é a divisão da sociedade em classes que disputam uma hegemonia (FRIGOTTO, 2007; FRIGOTTO; CIAVATTA;RAMOS, 2005; KUENZER, 2006, 2010).

Frigotto (2007) aponta para a interpretação de uma educação baseada na desigualdade e tratada como produto e condição do projeto dominante da sociedade brasileira.

Para a burguesia brasileira não há a necessidade de universalização da Educação Básica e sua relação com a Educação Profissional e Tecnológica é que esta seja restrita para formar o "cidadão produtivo" submisso e adaptado às necessidades do capital e do mercado (FRIGOTTO, 2007, p. 1131).

Esse modelo se pauta em um capitalismo dependente dos grandes centros financeiros,e, em uma análise histórica e crítica do processo de trabalho, observa-se que as relações existentes na venda da força de trabalho são fetichizadas na sociedade, sendo concebidas com naturalidade como se não dependessem da ação humana.

A superação dessa relação entre o capital e o trabalho envolve a elaboração de currículos integrados na Educação Profissional, com a necessidade de uma discussão ampla com toda a comunidade da qual emergem os tais cursos,que devem contemplar no processo formativo a autonomia e emancipação dos sujeitos.

A formação integrada possui um sentido revolucionário, que permitiria, na perspectiva da classe trabalhadora, uma formação do trabalhador com aspectos do trabalho em seu sentido ontológico, bem como aspectos da cultura, da tecnologia, das artes etc. Porém, "ao contrário, predomina, ainda, de um lado, a visão sobre o ensino médio profissionalizante como compensatória e, de outro, a defesa de um ensino médio propedêutico, sendo a 
profissionalização um processo específico e independente" (CIAVATTA; RAMOS, 2011, p. $35)$.

Além disso, cabe ressaltar que as dificuldades para integração também podem estar relacionadas, muitas vezes, à forma impositiva como estaé apresentada. Muitos professores, além de não a conhecerem conceitualmente, possuem ainda concepções conservadoras sob o ponto de vista pedagógico e político a respeito da integração. Também, fomentando essas dificuldades, estão as condições materiais, a forma de gestão das instituições que, muitas vezes, não ocorre democraticamente e, ainda, a parcela de professores relacionados ao trabalho precarizado, como os professores substitutos, o que dificulta o seu envolvimento com essa perspectiva.

Essas dificuldades podem ser superadas, como apontam muitos estudos de pesquisadores da relação Trabalho e Educação (FRIGOTTO; CIAVATTA; RAMOS, 2005; KUENZER;GRABOWSKI, 2006), o que significa a possibilidade de, concretamente, implantar uma formação integrada que contemple aspectos da ciência, tecnologia, cultura, artes com as dimensões ontológicas do trabalho humano e as relações de produção.

No contexto da Educação Profissional, observa-se, nos últimos anos, uma crescente expansão dessa modalidade, principalmente com a criação dos Institutos Federais de Educação, Ciência e Tecnologia, através da Lei 11.892/08. Nesta lei, institui-se a rede federal de Educação Profissional e Tecnológica que compreende, além dos Institutos Federais, as escolas técnicas vinculadas às universidades federais, os Centros Federais de Educação Tecnológica do Rio de Janeiro e Minas Gerais e a Universidade Tecnológica Federal do Paraná (BRASIL, 2008).

Pela Lei 11.892/08, os Institutos Federais possuem a finalidade de ofertar Educação Profissional e Tecnológica em todos os níveis e modalidades e promover a integração e a verticalização da Educação Profissional, desde a Educação Básica até a Educação Superior, otimizando a infraestrutura física, os quadros de pessoal e os recursos de gestão. Segundo a legislação que os instituiu, os Institutos Federais devem constituir-se como centros de excelência na oferta do ensino de ciências, em geral, e de ciências aplicadas, em particular, e qualificar-se como referência no apoio à oferta do ensino de ciências nas instituições públicas de ensino, oferecendo capacitação técnica e atualização aos docentes.

Uma análise da lei que criou os Institutos Federais permite, por um lado, verificar a grande proximidade com os setores produtivos, já que os Institutos Federais devem gerar e adaptar soluções sob o ponto de vista técnico e tecnológico, beneficiando os arranjos produtivos locais, ou seja, os Institutos Federais estão direcionados para obedecer à lógica dos interesses do processo produtivo capitalista. Para Otranto (2010, p. 11), "os institutos federais são, em última análise, mais um modelo alternativo à "universidade de pesquisa", que vem sendo implementado na América Latina, nos últimos anos, a partir do incentivo explícito do Banco Mundial”.

Ainda, segundo a autora, na proposta político-educacional-financeira do Banco Mundial, de criação de instituições de educação superior que tenham custos inferiores aos das universidades, no que se refere aos cursos superiores técnicos, ganha especial destaque a alegação de que esses cursos seriam mais flexíveis, portanto mais integrados ao sistema produtivo, e de menor custo que o universitário tradicional.

\section{Apresentação e análise dos dados}

Conforme descrito anteriormente, na análise das entrevistas utilizamos a Análise de Conteúdo. Assim, após ler e reler as respostas dos entrevistados, os dados, agora já identificados como unidades de registro, foram novamente agrupados por respostas afins, visando a compreender as vozes que se manifestavam no conteúdo obtido. Dessa 
interpretação emergiram as seguintes categorias gerais: homem, natureza e trabalho. As unidades de análise que as compõem são as seguintes: Homem produz impactos à natureza; Relação trabalho, emprego e natureza; Perspectiva interdisciplinar.

Para a apresentação da análise os alunos tiveram seus nomes mantidos em sigilo, conforme solicitação. Dessa forma, eles estão identificados por códigos, que foram atribuídos de maneira aleatória, sem qualquer relação com a sequência real da realização das entrevistas, de MA1 a MA12.

$\mathrm{Na}$ unidade de análise, o Homem produz impactos à natureza, mostra que a compreensão dos alunos está inserida em uma lógica em que há uma cisão entre o homem e a natureza. A fala do participante MA4 expressa esta compreensão:

Hoje em dia tá bastante conflituosa essa relação homem e natureza, talvez porque as pessoas não entendam que elas têm que preservar onde elas vivem né, por causa que, tem que preservar onde elas vivem para assim continuar vivendo. Por causa que as pessoas só acham que, até mesmo aqui na escola acha para quê que se serve um técnico em Meio Ambiente? Não serve para nada. Só que eles não entendem que eles precisam preservar o lugar que eles estão morando pra continuar vivendo. Muitas vezes parece assim que eles não estão nem aí para os filhos, para os netos, porque eles acham que sempre vai continuar dessa maneira, só que as vezes é com grandes, com grandes mudanças climáticas que eles começam a perceber que sim, que o mundo ta mudando, que o mundo ta mudando e que isso uma hora vai, vai impacta na própria vida dele porque de maneira que eles não, que eles não escutaram quando as pessoas estavam apenas falando e agora que eles estão sentindo que eles estão vendo que sim, que umas coisas precisam ser mudadas (PART. MA4).

Essa opinião, de que o homem causa impactos à natureza, como uma cisão entre o homem e a natureza, aparece também de outra forma, na fala dos alunos, quando eles abordam a respeito das atribuições de um Técnico em Meio Ambiente. Segundo o participante MA11, a respeito das atribuições de sua futura profissão em uma empresa:

$\mathrm{Eu}$ acho que, que como a gente ta aprendendo em Tratamento, a gente tem que diminuir o, a disponibilidade de coisas, mas sem perder a lucratividade, por exemplo, tu pode usar menos água e tal, mas sem diminuir a produtividade porque, tudo que querem é aumentar a quantidade de consumo, então a gente não pode chegar lá e dizer, vamos abaixar, para ter menos, pra a empresa ter menos dinheiro, vamos dizer assim (PART.MA11).

Ao expressar, por exemplo, que se deve diminuir o consumo de água, que seria uma atitude de minimizar impactos, mas não interferir na lucratividade, ele demonstra a compreensão de uma formação voltada aos interesses do mercado e não ao interesse das concretas necessidades humanas, em uma relação equilibrada com a natureza. É uma compreensão de que o homem parece estar à parte da natureza, que não expressa, conforme Foster (2011), uma relação metabólica entre o homem e a natureza.

O expressar a Educação Ambiental como forma de conscientização para diminuir o impacto ambiental corrobora essa compreensão de cisão entre o homem e a natureza. Isso pode ser identificado na fala do participante MA9:

Educação Ambiental. Acho que é algo que as pessoas deveriam ter em si. Desde a sua essência, desde a sua infância, quando se diz, ah, tem que educar o teu filho né, e as pessoas pensam em educar o filho somente naquela parte mais social e mais... e também é um pouco ambiental, mas, esquecem de educar o filho a parte ambiental a parte do respeito ao meio ambiente, acho que isso deveria existir, mas infelizmente não existe e eu considero a Educação Ambiental como uma ferramenta, que é transversal, que deveria ser utilizada em todas as disciplinas e infelizmente não é, ela que fala da relação homem natureza né, e qual a melhor forma de manter essa relação sem causar, causando o mínimo de impacto possível (PART. MA9). 
A compreensão de que a Educação Ambiental permitiria a conscientização para diminuir os impactos ambientais não está de acordo com a perspectiva de um processo de transformação social que envolva um novo patamar de produção das necessidades do homem. As opiniões exemplificam compreensões associadas à corrente Conservacionista/Recursista e à corrente Resolutiva de Educação Ambiental, descritas por Sauvé (2005). Também podem ser associadas às concepções de Educação Ambiental Convencional, criticadas por Loureiro (2009) e Guimarães (2004), pois são compreensões relacionadas a comportamentos individuais ou atividades que não possuem uma instrumentalização do ponto de vista epistemológico

Essas falas expressam uma compreensão em que não há um comprometimento com o processo de transformações significativas da realidade, pois envolvem processos que são tratados como atos comportamentais, com pouca articulação com o coletivo e problematização para transformação da realidade de vida, fazendo com que esses processos não envolvam aspectos políticos das questões ambientais.

Tal compreensão da cisão entre o homem e a natureza, presente nas entrevistas, pode indicar a perspectiva de Educação Profissional em que há uma separação entre o trabalho manual e o trabalho intelectual, pois não aparece nas falas um direcionamento do processo formativo para uma discussão crítica que permita a compreensão do capitalismo com as contradições existentes entre o capital e o trabalho na atuação profissional. Isso pode ser identificado, mais especificamente, na fala do aluno MA6 a respeito da atuação do Técnico em Meio Ambiente:

Tentar pensar uma forma, um jeito novo de produzir, não parar de produzir, eu acho, mas produzir de um jeito diferente. Então minimizar o máximo os impactos ambientais, sei lá, em todos os sentidos tanto na indústria quanto em casa, quanto numa loja, em qualquer lugar (PART. MA6).

Essa opinião expressa pelo aluno não permite compreender a influência do modo de produção capitalista no processo de formação profissional, em que existe uma cisão entre trabalho intelectual e trabalho manual, que oculta uma materialidade que é a divisão da sociedade em classes que disputam uma hegemonia (FRIGOTTO, 2007; FRIGOTTO; CIAVATTA;RAMOS, 2005; KUENZER, 2006, 2010).

$\mathrm{Na}$ unidade de análise, Relação trabalho, emprego e natureza, a compreensão de trabalho e emprego pelos alunos também demonstra uma visão que está de acordo com a ideologia dominante, como o trabalho vinculado a uma renda, realização pessoal e/ou obrigações. Isso aparece na opinião do participante MA5:

Trabalho, trabalho? Uma experiência pessoal. Antes eu tava visando trabalhar para conseguir dinheiro. Isso eu também continuo, mas não tanto, porque o trabalho tem que ser alguma coisa que faça bem, que tu te sinta bem, para fazer determinada coisa, determinada atividade, enfim, porque... até tem um cara que fala que o trabalho, não sei o que o homem, como que... como é que é mesmo... que dá valor ao homem, entendeu, não é o que homem em si faz. O trabalho foi visto, passar dos tempos com várias modificações, mas tu pode fazer alguma coisa que tu te sinta bem ou tu pode sentir fazer alguma coisa que tu não te sente. Vai ser como tu encara a tua vida e como tu vai fazer da tua vida algo legal. Tu pode ser só mais um operário e alguém frustrado ou não (PART. MA5).

Posteriormente, em sua fala sobre o que é emprego diz:

Eu acho que não. Trabalho ta realizando uma atividade. Tu ta fazendo algo. Tu ta dedicando de verdade. Emprego tu ta lá para fazer uma função específica, tipo tu ta... ambos tem a questão do lucro, mas sei lá. Emprego é algo que eu me sentiria mais um objeto. Empregado (PART. MA5). 
Esse participante faz uma diferenciação entre trabalho e emprego, relacionando-os com lucro. Embora ambos sejam diferenciados, o participante demonstra, no caso do conceito de trabalho, sua relação a algo que faça a pessoa se sentir bem, não aparecendo de forma mais explícita o trabalho como uma relação com a natureza, bem como aparece o trabalho, e também emprego, como geradores de lucro. A opinião do participante MA12 também mostra essa diferenciação:

Trabalhar, sei lá. A, não sei, tipo. Uma definição de trabalho? Teria que ser a gente exercer alguma função bem na sociedade, que a gente goste né. Teria que ser. Emprego é tu trabalhar e fazer alguma função, mas nem sempre tu gosta né. Tu tem que trabalhar (PART. MA12).

Esse participante faz uma diferenciação, relacionando o trabalho a uma função social, enquanto o emprego se relaciona a algo que a pessoa não gosta. Da mesma forma, faz uma diferenciação relacionando o trabalho a algo que é característico dos seres humanos, enquanto o emprego se relaciona às obrigações. Também, não aparece de forma mais explícita, em suas respostas, o trabalho como uma relação entre o homem e a natureza.

Nessas duas primeiras opiniões, o emprego aparece em uma perspectiva mais desfavorável ao homem, se comparada com a abordagem sobre trabalho, e está relacionado a uma visão que está de acordo com o modelo de produção vigente. Nessa visão, tanto trabalho quanto emprego apresentam uma compreensão distorcida da realidade, mostrando um processo dealienação. $\mathrm{O}$ emprego se relaciona a um processo fetichizado, em que há uma exploração do trabalhador, fazendo com que ele não se identifique com o processo de produção. O trabalho não é compreendido em seu sentido ontológico, ou seja, como um processo metabólico entre o homem e a natureza (FOSTER, 2011).

O participante MA8 se expressa sobre a natureza diferenciando-a sobre o que ele entende de meio ambiente e a relação com o trabalho:

[...] natureza é o espaço lá sozinho ainda não tocado pelo homem. É aquela parte lá que a gente não foi, não destruiu, não desmatou. E meio ambiente é tudo do resto. Onde a gente vive, onde a gente trabalha, estuda, nossa casa, onde a gente ta mais inserido (PART. MA8).

Embora esse participante demonstre uma compreensão de cisão entre o homem e a natureza, descrevendo-a como algo afastado e intocado pelo homem, como discutido na unidade de análise anterior, ele demonstra, também, a compreensão de que o trabalho se relaciona com o meio ambiente. Isso aparece de forma mais específica ainda na fala do participante MA9:

Eu acho que tudo ta relacionado com o meio ambiente né, de uma forma ou de outra, se hoje existe trabalho é porque existe exploração dos recursos naturais. Porque se não houvesse a exploração dos recursos naturais, não acredito que não haveria porque se trabalhar. Porque se trabalha para se transformar a natureza em matéria prima para alguma outra coisa que será utilizada para outros fins e assim sucessivamente (PART. MA9).

Nessa opinião, o trabalho não aparece como um processo de interação com a natureza, ou como um processo metabólico, e sim, novamente, como um processo de exploração da natureza pelo homem, causando impactos.

Essas compreensões que envolvem as concepções de trabalho, emprego e natureza estão relacionadas com perspectivas de Educação Ambiental que não contemplam um processo crítico das questões ambientais, pois não articulam a relação entre o homem e a natureza, através do trabalho, como processo de equilíbrio na utilização dos recursos naturais por meio das reais necessidades humanas, articulado com o envolvimento coletivo dos sujeitos, ou seja, como um processo metabólico entre o homem e natureza. Assim, são 
compreensões sobre trabalho que podem estar associadas à corrente Conservacionista/Recursista e à corrente Resolutiva de Educação Ambiental, descritas por Sauvé (2005), bem como às concepções de Educação Ambiental Convencional, criticadas por Loureiro (2005) e Guimarães (2004).

$\mathrm{Na}$ unidade de análise Perspectiva Interdisciplinar se considerou como ocorre a processualidade da relação entre as diferentes áreas do conhecimento e como as concepções de homem, natureza e trabalho são entendidas nessa relação. A opinião do participante MA1 mostra a sua compreensão a respeito da aproximação realizada entre disciplinas e as questões ambientais:

Eu acho que na medida do possível os professores eles tentam assim... Meio ambiente é um curso novo assim no campus né, relativamente. Então eu acho que os professores fazem o possível, a gente tem professores bons, a gente tem professores qualificados, eles tentam assim fazer a interligação para passar o conhecimento mais adequado para a gente, eu acho que na medida do possível sim, mas acho que a gente teria... precisaria de mais sair como técnico qualificado para o mercado de trabalho, a gente precisa de mais ainda (PART. MA1).

Assim, no entendimento desse participante ocorrem aproximações entre disciplinas e a questão ambiental, mas demonstrando certa insatisfação em relação à formação técnica do curso. Ou seja, para ele, as aproximações entre disciplinas e a questão ambiental parecem ser limitadas e, ao mesmo tempo, podem não ser suficientes para a sua formação e, nesse processo formativo, compreende que o técnico precisa ser formado para atuar no mercado de trabalho. Um entendimento do trabalho para oferta no mercado, segundo o capitalismo, e não como um processo de interação entre o homem e a natureza.

Verifica-se, nessas compreensões, que não se problematiza que as questões ambientais estão diretamente relacionadas ao modo de produção capitalista que, com seus atores, possui interesses antagônicos às questões ambientais e também sociais. Conforme Frigotto (2010) e Kuenzer (2006), não há uma formação que contemple conhecimentos da ciência, da tecnologia e da cultura, com sujeitos capazes de tomadas de decisão coletiva para o bem comum da sociedade.

Por outro lado, a opinião do participante MA3 mostra uma compreensão ao tratar os aspectos sociais e econômicos nas aproximações entre as disciplinas:

É uma coisa que a gente vê bem em sala de aula. Falando em interligar as disciplinas História, e Aspectos Culturais Regionais se interligam bastante em relação a isso. Que a professora sempre botou aquela coisa assim: tu tem que pesar na balança o que é mais importante. Se é a questão social, questão ambiental. Porque tem todo uma questão. Por exemplo, a gente via muito a parte do Xingu, Belo Monte de toda aquela interligação entre a população que reside naquela mata. A mata que tem que preservar e o rio que tu quer usar como fonte de energia. Então são três coisas muito importantes que tu tem que frisar e ver o quê que é importante. Por exemplo, para a empresa privada o ideal era tirar a população dali e fazer hidrelétrica, né. Mas para nós como técnico, a nossa visão é deixar a população ali que não ta interferindo no meio ambiente, vamos dizer, porque a relação homem, natureza não ta interferindo do que tu trazer uma hidrelétrica que vai prejudicar essa população. Porque a população, muitos casos, tava ficando sem lugar nenhum para morar e o governo tava dando jeito em nada. E sem falar que tu perdia a maior diversidade que tinha por causa que as áreas que foram alagadas. Então tu tem que pesar isso na balança. Mas aí que eu digo que é meio complicado agir com técnico. Porque, quando a professora trouxe esse senso critico tudo, mostrando para nós de pesar na balança, os técnicos que diziam que a hidrelétrica, para ser criada ali não tinha condições eram demitidos. Então assim, o choque... (PART. MA3).

Essa fala expressa o senso crítico no processo formativo, pois mostra as contradições existentes, através da discussão promovida nas disciplinas, que estão presentes devido às 
condições impostas pelo modo de produção capitalista. Também,mostra uma situação na qual o currículo e as perspectivas teóricas dos professores permitem uma formação com aspectos críticos e emancipatórios dos alunos. São compreensões que se aproximam de uma formação que permitiria a superação da dicotomia entre o trabalho manual e o trabalho intelectual, bem como a formação integrada entre a Educação Básica e a Educação Profissional. Conforme Frigotto (2010) e Kuenzer (2006), uma formação que contemple conhecimentos da ciência, da tecnologia e da cultura, com sujeitos capazes de tomadas de decisão coletiva para o bem comum da sociedade.

As compreensões envolvidas estão de acordo com as perspectivas da Educação Ambiental Crítica (LOUREIRO, 2009), pois o conhecimento não deriva de saberes desunidos e compartimentalizados, mas com os sujeitos possuindo um papel central no processo político de tomada de decisões. Também, está de acordo com as perspectivas da Educação Ambiental Emancipatória e Transformadora (QUINTAS, 2004), pois entende a preservação e defesa do meio ambiente e seu equilíbrio ecológico para as atuais e futuras gerações como um compromisso ético e dever do poder público e da coletividade.

\section{Considerações finais}

As concepções sobre homem, natureza e trabalho que emergiram neste estudo mostram que, no curso de Técnico em Meio Ambiente, há a compreensão de uma cisão existente entre o homem e a natureza. Isso apareceu nas falas quando expressaram que o homem causa impactos à natureza e com compreensões de uma formação voltada aos interesses do mercado. Segundotais compreensões, a Educação Ambiental permitiria a conscientização para diminuir os impactos ambientais. Também, emergiu a compreensão de que o trabalho humano, além de vinculado a uma renda, realização pessoal e/ou obrigações, é um processo de exploração da natureza pelo homem, causando impactos. O conceito de emprego aparece em uma perspectiva mais desfavorável ao homem, se comparada com a abordagem sobre trabalho, e possui uma relação que está de acordo com as concepções do modelo de produção vigente.

Ao analisar como ocorre a processualidade da relação entre as diferentes áreas do conhecimento, ou seja, na perspectiva interdisciplinar, emergiram compreensões em que as aproximações entre disciplinas e a questão ambiental parecem ser limitadas e insuficientes para a formação, na qual há um entendimento do trabalho para oferta no mercado, segundo o modo de produção capitalista. Emergiram, igualmente, compreensões em que o processo formativo do curso estaria mais voltado para uma conscientização das questões ambientais.

Assim, no curso de Técnico em Meio Ambiente, as compreensões de homem, natureza e trabalho implicaram concepções de Educação Ambiental relacionadas a aspectos direcionados a atitudes preservacionistas e mitigadoras, com um foco voltado a medidas de conscientização no trato do homem com a natureza, ou seja, uma compreensão de que a Educação Ambiental permitiria a conscientização para diminuir os impactos ambientais. Foram constatados, ainda, alguns indícios de compreensões relacionadas a perspectivas com um fundamento mais crítico da Educação Ambiental, mas embora esses aspectos tenham surgido na análise, não foi possível verificá-los de forma aprofundada. Contudo, tais indícios mostram a possibilidade de uso dessa abordagem no processo formativo.

Em relação às concepções de Educação Profissional, as compreensões se apresentaram relacionadas a um processo formativo que os qualifica para o mercado de trabalho, ou seja, compreensões em que, conforme as necessidades do processo produtivo, os sujeitos possuam uma formação profissional. Compreensões em que há uma separação entre o trabalho manual e o trabalho intelectual, conforme o modo de produção capitalista. 
A Educação Ambiental e Educação Profissional devem dialogar juntas, através da compreensão de que o trabalho, em sua essência ontológica, sendo uma relação metabólica entre o homem e a natureza, configure um elo na construção de sujeitos críticos e emancipados nas relações sociais e com o meio ambiente.

Para implementar uma proposta como essa, é necessário um trabalho com a comunidade, que envolva os cursos, principalmente a equipe pedagógica e os professores, através de estudos, discussões e debates, para que ocorra um entendimento sobre o que é uma formação integrada e a sua importância no processo formativo dos alunos. No entanto, a construção dessa proposta não pode ser impositiva. Deve ser realizada de forma clara, aberta e objetiva, possibilitando a todos os sujeitos envolvidos a liberdade necessária para que as tomadas de decisão ocorram democraticamente.

\section{Referências}

AVANZI, M. R.Ecopedagogia. In: LAYRARGUES, P.P. (Coord.) Identidades da Educação Ambiental Brasileira.Brasília: Ministério do Meio Ambiente, 2004. p. 35-49.

BARDIN, L.Análise de Conteúdo.Lisboa: Edições 70, 1977.

BRASIL. Lei $n^{\circ} 11.892$, de 29 de dezembro de 2008. Institui a Rede Federal de Educação Profissional, Científica e Tecnológica, cria os Institutos Federais de Educação, Ciência e Tecnologia, e dá outras providências.Brasília: Casa Civil, em: <http://www.planalto.gov.br/ccivil 03/ ato2007-2010/2008/lei/111892.htm>. Acesso em: 15 jul. 2012.

CARVALHO, I. C. M. Educação Ambiental:a formação do sujeito ecológico. São Paulo: Cortez, 2004.

CIAVATTA, M.; RAMOS, M. Ensino Médio e Educação Profissional no Brasil Dualidade e fragmentação.Retratos da Escola, Brasília, v. 5, n. 8, p. 27-41, jan/jun. 2011.

FRANCO, M.L. P. B. Análise de Conteúdo.2 ed.Brasília, Líber Livro, 2005.

FOSTER, J. B.A ecologia de Marx:materialismo e natureza. 3 ed. Rio de Janeiro: Civilização Brasileira, 2011.

FRIGOTTO, G.A Relação da Educação Profissional e Tecnológica com a Universalização da Educação Básica. Educação \& Sociedade, Campinas, v. 28,n. 100, p. 1129-1152, out, 2007.

FRIGOTTO, G.Educação e a Crise do Capitalismo Real.6ed. São Paulo: Cortez, 2010.

FRIGOTTO, G.; CIAVATTA, M.; RAMOS, M. A política de educação profissional no governo Lula:um percurso histórico controvertido.Educação \& Sociedade, Campinas,v. 26 - Especial, n. 92, p. 1087-1113, out, 2005.

GUIMARÃES, M. Educação Ambiental Crítica. In: LAYRARGUES, P. P.(Coord.) Identidades da Educação Ambiental Brasileira.Brasília: Ministério do Meio Ambiente, 2004. p. 25-34.

KUENZER, A. Z. A educação profissional nos anos 2000:a dimensão subordinada das políticas de inclusão. Educação \&Sociedade, Campinas, v. 27 - Especial, n. 96, p. 877-910, out, 2006.

KUENZER, A. Z.O ensino médio no plano nacional de educação 2011-2020: superando a década perdida?Educação \& Sociedade, Campinas, v. 31, n. 112, p. 851-873, jul/set, 2010. 
KUENZER, A. Z.; GRABOWSKI, G. Educação Profissional:desafios para a construção de um projeto para os que vivem do trabalho.Perspectiva, Florianópolis, v. 24,n. 1, p. 297-318, jan/jun, 2006.

LOUREIRO, C. F. B. Educação ambiental transformadora. In: LAYRARGUES, P. P. (Coord.).Identidades da Educação Ambiental Brasileira.Brasília: Ministério do Meio Ambiente, 2004. p. 65-84.

LOUREIRO, C. F. B. Trajetórias e Fundamentos da Educação Ambiental. São Paulo: Cortez, 2009.

OTRANTO, C. R. Criação e implantação dos institutos federais de educação, ciência e tecnologia IFETs.Revista RETTA, Rio de Janeiro, v.1 , n. 1, p. 89-110, jan/jun, 2010.

QUINTAS, J. S. Educação no processo de gestão ambiental: uma proposta de educação ambiental transformadora e emancipatória. In: LAYRARGUES, P. P. (Coord.). Identidades da Educação Ambiental Brasileira.Brasília: Ministério do Meio Ambiente, 2004. p. 113-140.

RUSCHEINSKY, A. Atores sociais e meio ambiente. In: LAYRARGUES, P. P. (Coord.). Identidades da Educação Ambiental Brasileira.Brasília: Ministério do Meio Ambiente, 2004. p. 51-63.

SAUVÉ, L. Uma cartografia das correntes em educação ambiental. In: SATO, M.;

CARVALHO, I. C. M. (Orgs.) Educação Ambiental:pesquisas e desafios.Porto Alegre: Artmed, 2005. p. 17-44.

UNESCO-UNEP International Environmental Education Programme (1975-1987): Unesco-UNEP International Congress on Environmental Education and Training (Moscow, USSR, 17-21 August 1987) 